\title{
Clinical Performance of Monocyte Distribution Width for Early Detection of Sepsis in Emergency Department Patients: A Prospective Study
}

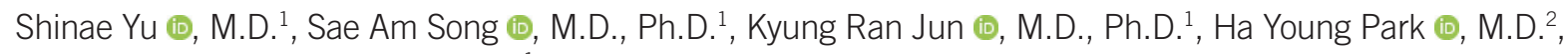 \\ and Jeong Nyeo Lee $\mathbb{C}$, M.D., Ph.D. ${ }^{1}$ \\ Departments of ${ }^{1}$ Laboratory Medicine and ${ }^{2}$ Emergency Medicine, Haeundae Paik Hospital, Inje University College of Medicine, Busan, Korea
}

\section{Dear Editor,}

Most patients with sepsis are admitted through the emergency department (ED), and their outcome is significantly worse if the diagnosis and treatment are delayed [1, 2]. Therefore, early detection and treatment of sepsis are important in ED patients. Monocyte distribution width (MDW) is increased in patients with sepsis, making it a potential marker for the early diagnosis of sepsis [3, 4]. MDW is a measurable marker that can be obtained simultaneously with complete blood count (CBC). Thus, results can be obtained quickly, and additional blood collection from the patient for sepsis evaluation is not required. We evaluated the usefulness of MDW in predicting sepsis or septic shock using the Sepsis-3 criteria in patients visiting the ED [5].

We enrolled 1,234 Korean patients aged $>18$ years with a fever of $\geq 37.5^{\circ} \mathrm{C}$ and/or symptoms such as hypotension and mental deterioration, whose initial evaluation included $\mathrm{CBC}$ and $\mathrm{C}$ reactive protein (CRP) tests on suspicion of infection, conducted within two hours of presenting to the ED at Haeundae Paik Hospital, Busan, Korea, between May and August 2019. This study was approved by our Institutional Review Board (HPIRB 201812-003), and the requirement for informed consent was waived because there is less than minimum risk to patients when using surplus samples. Samples for CBC, white blood cell (WBC) dif- ferential count, and MDW were collected in $\mathrm{K}_{2}$-EDTA tubes (Becton Dickinson, Plymouth, UK) and analyzed in a UniCel DxH 900 analyzer (Beckman Coulter, Inc., Brea, CA, USA). CRP and procalcitonin were measured from sera obtained by the centrifugation of samples collected in VACUETTE ${ }^{\circledR}$ CAT Serum Separator Clot Activators (Greiner Bio-One GmbH, Kremsmünster, Austria) at 1,680 $\times$ g for 10 minutes. CRP was analyzed using Hitachi 7600 instrument (Hitachi, Tokyo, Japan) and Nanopia CRP (Sekisui Medical Co., Ltd., Tokyo, Japan), and procalcitonin was analyzed using cobas e 411 analyzer (Roche Diagnostics $\mathrm{GmbH}$, Mannheim, Germany) and Elecsys BRAHMS Procalcitonin (Roche Diagnostics $\mathrm{GmbH}$ ). All procedures were performed according to the manufacturers' instructions. For statistical analyses, the chi-square test or Fisher's exact test was used for categorical variables, and the Mann-Whitney $U$ test or Kruskal-Wallis test was used for continuous variables. Receiver operating characteristic (ROC) curve analysis was performed to assess the sensitivity and specificity of MDW and blood count parameters to predict sepsis and septic shock. Optimal cut-offs for MDW and other laboratory markers were estimated using the classical Youden index. All statistical analyses were carried out using SPSS version 24.0 (IBM Corp., Armonk, NY, USA), and $P<0.05$ was considered statistically significant.
Received: April 6, 2021

Revision received: July 14, 2021

Accepted: September 15, 2021

Corresponding author: Jeong Nyeo Lee, M.D., Ph.D.

Department of Laboratory Medicine, Haeundae Paik Hospital, Inje University College of Medicine, 875 Haeun-daero, Haeundae-gu, Busan 48108, Korea Tel: +82-51-797-3190, Fax: +82-51-797-3194

E-mail: jeong418@paik.ac.kr

\section{(c) (1) (9)}

(C) Korean Society for Laboratory Medicine

This is an Open Access article distributed under the terms of the Creative Commons Attribution Non-Commercial License (https://creativecommons.org/licenses/by-nc/4.0) which permits unrestricted non-commercial use, distribution, and reproduction in any medium, provided the original work is properly cited. 


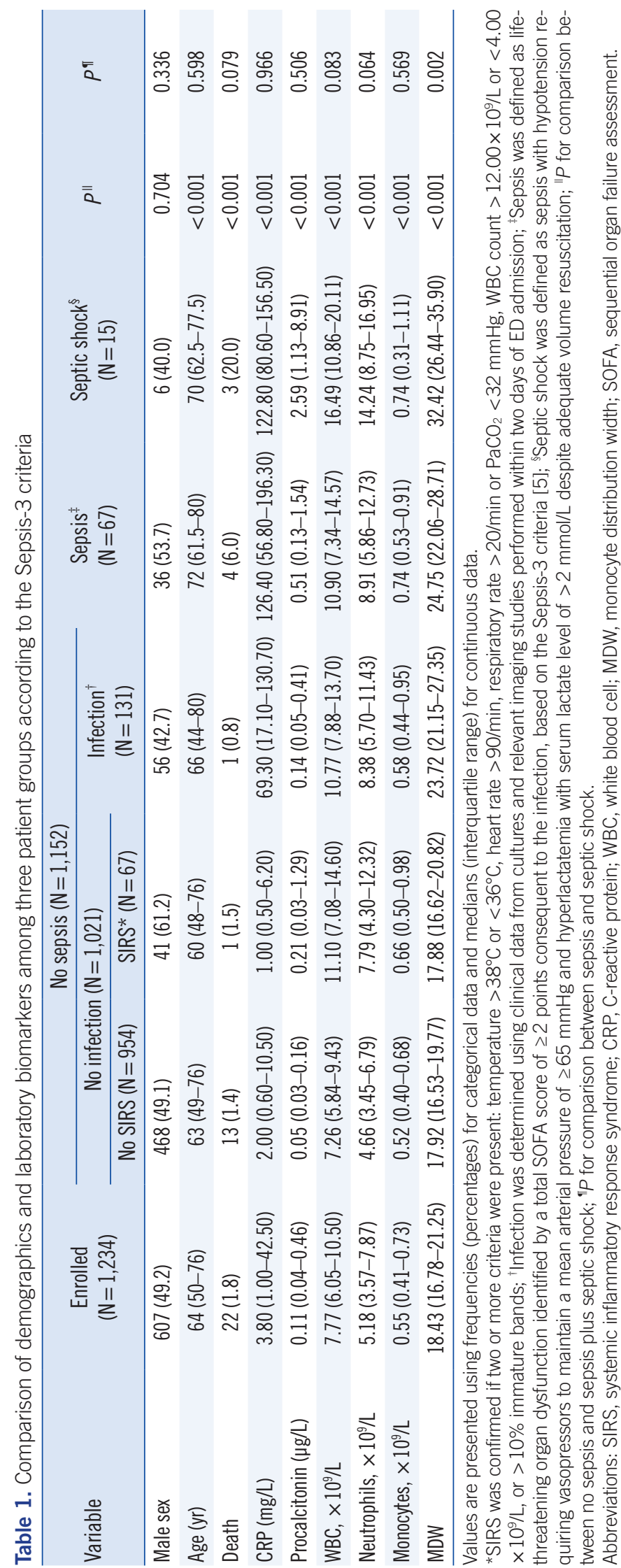

All laboratory markers associated with sepsis, including MDW, were higher in patients with sepsis and septic shock than in those without sepsis (Table 1). We confirmed hepatitis $A$ in two of the 67 sepsis patients, both of whom had high MDW (28.65 and 29.32). Two of three fungal sepsis patients and both fungal septic shock patients, infected with Candida albicans or other yeastlike fungus confirmed by culture from urine or respiratory samples, also had high MDW $(26.52,34.71,33.94$, and 37.25, respectively). MDW increased significantly in COVID-19 patients, especially in those hospitalized in the intensive care unit [6, 7]. MDW increases with progression from infection to sepsis and is the highest in sepsis patients with severe organ dysfunction [3]. This study demonstrated that MDW was the only biomarker that differed significantly between patients with sepsis and septic shock (Table 1).

The area under the ROC curve of MDW was the highest (0.896, 95\% confidence interval [Cl]: 0.868-0.923), followed by that of CRP (0.894, 95\% Cl: 0.866-0.923), PCT (0.793, 95\% Cl: $0.742-$ $0.844)$, and WBC count $(0.692,95 \% \mathrm{Cl}: 0.623-0.762)$. The statistically best cut-offs for predicting sepsis and septic shock were $31.750 \mathrm{mg} / \mathrm{L}$ for CRP, $0.099 \mathrm{\mu g} / \mathrm{L}$ for procalcitonin, 9.614 $\times 10^{9} / \mathrm{L}$ for WBC count, and 21.935 for MDW, the latter of which is higher than that (20.0) reported by Crouser, et al. [4], similar to that (21.9) reported by Polilli, et al. [8], and lower than that (23.5) reported by Agnello, et al. [9]. Whole-blood samples collected in $\mathrm{K}_{2}$-EDTA tubes reportedly yield lower MDW than those collected in $K_{3}$-EDTA tubes [9]. Therefore, the MDW cut-offs for samples collected in $\mathrm{K}_{2}$-EDTA in those previous reports and our study were lower than those for samples in $K_{3}$-EDTA $[4,8,9]$.

The highest sensitivity of 93.9\% was achieved using 20 as the MDW cut-off. The highest specificity of $91.8 \%$ was achieved when the MDW cut-off of 21.935 was used in addition to a WBC cut-off of $9.614 \times 10^{9} / \mathrm{L}$. The specificities of CRP and procalcitonin increased when combined with the MDW results (Table 2).

In conclusion, MDW is a useful marker for sepsis screening in the ED because it shows high sensitivity when used as a sole marker and high specificity when combined with other markers. Therefore, MDW may be useful for early detection of sepsis, prediction of sepsis severity, and effective clinical decision making, before other biomarkers or culture results and imaging interpretations become available.

\section{ACKNOWLEDGEMENTS}

None. 
Table 2. Sensitivity and specificity of laboratory biomarkers for predicting sepsis and septic shock

\begin{tabular}{|c|c|c|c|}
\hline Laboratory biomarker & Cut-off & Sensitivity (95\% Cl) & Specificity (95\% Cl) \\
\hline \multirow{2}{*}{ MDW } & 21.935 & $84.1 \%(74.0-91.0)$ & $83.0 \%(80.7-85.1)$ \\
\hline & 20 & $93.9 \%(85.7-97.7)$ & $70.1 \%(67.3-72.7)$ \\
\hline WBC count, $\times 10^{9} / \mathrm{L}$ & 9.614 & $64.6 \%(53.2-74.7)$ & $70.7 \%(68.0-73.3)$ \\
\hline $\mathrm{CRP}(\mathrm{mg} / \mathrm{L})$ & 31.750 & $90.1 \%(81.0-95.3)$ & $76.6 \%(74.0-79.0)$ \\
\hline Procalcitonin ( $\mu \mathrm{g} / \mathrm{L})$ & 0.099 & $90.5 \%(80.9-95.8)$ & $54.4 \%(48.8-59.8)$ \\
\hline \multirow[t]{4}{*}{ MDW plus WBC count, $\times 10^{9} / \mathrm{L}$} & MDW: 21.935 & & \\
\hline & WBC: 9.614 & $54.9 \%(43.5-65.8)$ & $91.8 \%(90.0-93.2)$ \\
\hline & MDW: 20 & & \\
\hline & WBC: 9.614 & $59.8 \%(48.3-70.3)$ & $87.5 \%(85.4-89.3)$ \\
\hline \multirow[t]{4}{*}{ MDW plus CRP (mg/L) } & MDW: 21.935 & & \\
\hline & CRP: 31.750 & $77.8 \%(66.9-86.0)$ & $88.2 \%(86.2-90.0)$ \\
\hline & MDW: 20 & & \\
\hline & CRP: 31.750 & $85.2 \%(75.2-91.8)$ & $84.5 \%(82.2-86.5)$ \\
\hline \multirow[t]{4}{*}{ MDW plus procalcitonin ( $(\mu \mathrm{g} / \mathrm{L})$} & MDW: 21.935 & & \\
\hline & procalcitonin: 0.099 & $78.4 \%(67.0-86.8)$ & $73.4 \%(68.2-78.0)$ \\
\hline & MDW: 20 & & \\
\hline & procalcitonin: 0.099 & $83.8 \%$ (73.0-91.0) & $65.3 \%(59.8-70.3)$ \\
\hline
\end{tabular}

Abbreviations: MDW, monocyte distribution width; WBC, white blood cell; CRP, C-reactive protein; Cl, confidence interval.

\section{AUTHOR CONTRIBUTIONS}

All authors contributed to the study conception and design. Yu S, Song SA, Jun KR, and Park HY investigated and interpreted the results. Yu S, Song SA, and Jun KR curated and analyzed the data. Yu S wrote the first draft of the manuscript. Lee JN supervised the study. All authors reviewed and edited the manuscript and agreed to publish the final manuscript.

\section{CONFLICTS OF INTEREST}

None declared.

\section{RESEARCH FUNDING}

The statistical analysis of this study received financial support from Inje University Haeundae Paik Hospital.

\section{ORCID}

Shinae Yu https://orcid.org/0000-0002-9527-5853 Sae Am Song Kyung Ran Jun https://orcid.org/0000-0002-3574-1621 https://orcid.org/0000-0001-8904-2327
Ha Young Park

Jeong Nyeo Lee

https://orcid.org/0000-0003-3204-7578

https://orcid.org/0000-0001-6030-8283

\section{REFERENCES}

1. Ferrer R, Martin-Loeches I, Phillips G, Osborn TM, Townsend S, Dellinger RP, et al. Empiric antibiotic treatment reduces mortality in severe sepsis and septic shock from the first hour: results from a guidelinebased performance improvement program. Crit Care Med 2014;42: 1749-55

2. Husabø G, Nilsen RM, Flaatten H, Solligård E, Frich JC, Bondevik GT, et al. Early diagnosis of sepsis in emergency departments, time to treatment, and association with mortality: an observational study. PLoS One 2020;15:e0227652

3. Crouser ED, Parrillo JE, Seymour C, Angus DC, Bicking K, Tejidor L, et al. Improved early detection of sepsis in the ED with a novel monocyte distribution width biomarker. Chest 2017;152:518-26.

4. Crouser ED, Parrillo JE, Seymour CW, Angus DC, Bicking K, Esguerra VG, et al. Monocyte distribution width: a novel indicator of sepsis-2 and sepsis-3 in high-risk emergency department patients. Crit Care Med 2019;47:1018-25.

5. Singer M, Deutschman CS, Seymour CW, Shankar-Hari M, Annane D, Bauer M, et al. The third international consensus definitions for sepsis and septic shock (Sepsis-3). JAMA 2016;315:801-10.

6. Lippi G and Plebani M. The critical role of laboratory medicine during coronavirus disease 2019 (COVID-19) and other viral outbreaks. Clin Chem Lab Med 2020;58:1063-9.

7. Ognibene A, Lorubbio M, Magliocca P, Tripodo E, Vaggelli G, lannelli G, 
Yu S, et al.

MDW for early detection of sepsis in ED patients

et al. Elevated monocyte distribution width in COVID-19 patients: the contribution of the novel sepsis indicator. Clin Chim Acta 2020;509:22-4.

8. Polilli E, Sozio F, Frattari A, Persichitti L, Sensi M, Posata R, et al. Comparison of monocyte distribution width (MDW) and procalcitonin for early recognition of sepsis. PLoS One 2020;15:e0227300.

9. Agnello L, Bivona G, Vidali M, Scazzone C, Giglio RV, lacolino G, et al. Monocyte distribution width (MDW) as a screening tool for sepsis in the emergency department. Clin Chem Lab Med 2020;58:1951-7. 